\title{
In Haitian women and preschool children, iron absorption from wheat flour-based meals fortified with sodium iron EDTA is higher than that from meals fortified with ferrous fumarate, and is not affected by Helicobacter pylori infection in children
}

\author{
Isabelle Herter-Aeberli ${ }^{1 *}$, Kerline Eliancy ${ }^{2}$, Yanick Rathon ${ }^{3}$, Cornelia U. Loechl ${ }^{4}$, Joseline Marhône Pierre ${ }^{2}$ \\ and Michael B. Zimmermann ${ }^{1}$ \\ ${ }^{1}$ Laboratory of Human Nutrition, ETH Zurich, 8092 Zurich, Switzerland \\ ${ }^{2}$ Ministère de la Santé Publique et de la Population, HT 6110 Port au Prince, Haiti \\ ${ }^{3}$ Laboratoire Nationale de la Santé, HT 6110 Port au Prince, Haiti \\ ${ }^{4}$ International Atomic Energy Agency, 1400 Vienna, Austria \\ (Submitted 17 March 2017 - Final revision received 7 July 2017 - Accepted 14 July 2017)
}

\section{Abstract}

Fe fortification of wheat flour was proposed in Haiti to combat Fe deficiency, but Fe bioavailability from fortificants has never been investigated in Haitian women or preschool children, two key target groups. We aimed to investigate the bioavailability of ferrous fumarate (FeFum), NaFeEDTA and their combination from fortified wheat flour. We recruited twenty-two healthy mother-child pairs in Port au Prince, Haiti, for an Fe-absorption study. We administered stable Fe isotopes as FeFum or NaFeEDTA individually in low-extraction wheat flour bread rolls consumed by all participants in a randomised, cross-over design. In a final, identical meal, consumed only by the women, FeFum + NaFeEDTA was administered. We measured Fe absorption by using erythrocyte incorporation of stable isotopes $14 \mathrm{~d}$ after consumption of each meal, and determined Fe status, inflammatory markers and Helicobacter pylori infection. Fe absorption (geometric mean was $9.24(95 \%$ CI 6.35, 13.44) and 9.26 (95\% CI 7.00, 12.31) from FeFum and 13.06 (95\% CI 9.23, 19.10) and 12.99 (95\% CI 9.18, 18.39) from NaFeEDTA in mothers and children, respectively $(P<0.05$ between compounds). Fe absorption from FeFum + NaFeEDTA was 11.09 (95\% CI $7.45,17.34)$ and did not differ from the other two meals. H. pylori infection did not influence Fe absorption in children. In conclusion, in Haitian women and children, Fe absorption from NaFeEDTA was $40 \%$ higher than from FeFum, and the combination FeFum + NaFeEDTA did not significantly increase Fe absorption compared with FeFum alone. In the context of Haiti, where the high costs of NaFeEDTA may not be affordable, the use of FeFum at $60 \mathrm{mg}$ Fe/kg flour may be a preferable, cost-effective fortification strategy.

Key words: Iron absorption: Ferrous fumarate: Sodium iron EDTA: Flour fortification

Fe-deficiency anaemia remains a major public health problem worldwide. Based on national surveys, the WHO reported that a total of 800 million preschool children and women were anaemic in 2011, representing a global prevalence of $42.6 \%$ in preschool children and $38.2 \%$ in pregnant women and $29.4 \%$ in all women of reproductive age. It is estimated that $42-50 \%$ of global anaemia could be eliminated by improving $\mathrm{Fe}$ intakes ${ }^{(1)}$. With a Human Development Index of 0.471 , Haiti ranks amongst the twenty countries with the lowest development worldwide $^{(2)}$. The prevalence of anaemia is high in Haiti, with $62 \%$ of children and $37 \%$ of women of reproductive age affected.

Fe fortification of staple foods is considered the most practical, sustainable and cost-effective solution to control Fe deficiency ${ }^{(3)}$.
Wheat flour is a staple food in Haiti, with an estimated consumption of about $120 \mathrm{~g} / \mathrm{d}$ based on the production volume and the total population numbers. Only one flour mill exists in Haiti (Les Moulins d'Haiti), which produces about $60 \%$ of all flour consumed in the country. The remaining $40 \%$ are imported, mainly from the USA. To improve the nutritional situation in Haiti, the government has drafted a new fortification law foreseeing the addition of different micronutrients to flour, palm oil and salt (J Marhone, unpublished results). The currently discussed recommendation for Fe fortification is $30 \mathrm{mg} \mathrm{Fe} / \mathrm{kg}$ in the form of NaFeEDTA to all wheat flour sold in Haiti.

Fe is probably the most challenging nutrient when it comes to food fortification. Water-soluble Fe compounds generally show the highest bioavailability as they are highly soluble in gastric

Abbreviations: AGP, $\alpha 1$-acid glycoprotein; BIS, body Fe stores; CRP, C-reactive protein; FeFum, ferrous fumarate; SF, serum ferritin; TfR, transferrin receptor. 
juices. But they are also most likely to result in organoleptic changes of the fortified products, especially in hot and humid climates. Ferrous sulphate is the most commonly used watersoluble Fe fortificant for flour fortification, but it can cause rancidity and off-colours in stored flours. Ferrous fumarate (FeFum) is an Fe compound insoluble in water but soluble in dilute acid. It has been shown to be as bioavailable as ferrous sulphate in adults but causes less sensory changes in the fortified foods. NaFeEDTA is a water-soluble form of Fe that is better absorbed than ferrous sulphate from flours with a high phytate content. NaFeEDTA does not promote lipid oxidation in stored flours and may produce less sensory changes in these products compared with ferrous sulphate. However, NaFeEDTA is considerably more expensive (approximately 16 times the costs of ferrous sulphate per mg Fe); the costs for FeFum are about twice that of ferrous sulphate ${ }^{(4)}$.

Helicobacter pylori infection is common worldwide; it is estimated that approximately $50 \%$ of the global population is infected, with especially high rates in low-income countries. Depending on the chronicity of $H$. pylori infection as well as environmental and host factors, gastric acid production can be either increased, decreased or unchanged in infected persons $^{(5)}$. Previous studies are equivocal on whether H. pylori infection affects Fe absorption ${ }^{(6,7)}$.

As costs are an important issue in the flour fortification programme in Haiti, the aim of this study was to investigate Fe absorption from wheat flour fortified with FeFum, NaFeEDTA or a combination of the two in young women in Haiti and their preschool age children. We hypothesised that: (1) Fe absorption would be higher from NaFeEDTA alone or combined with FeFum, compared with FeFum alone, and (2) Fe absorption from both compounds would be lower in individuals infected with H. pylori.

\section{Methods}

\section{Participants}

Study participants were twenty-two mother-child pairs living in Port au Prince, Haiti. As two of the most vulnerable groups for Fe deficiency, we intended to include both young women and young children in the study. For convenience reasons in terms of logistics during recruitment, we decided to recruit mother-child pairs. The mothers were between 18 and 45 years of age, generally healthy, weighed $<65 \mathrm{~kg}$ and were neither pregnant nor breast-feeding. The children were between 2.5 and 5 years of age, generally healthy and neither wasted $(<-2 z$ scores for weight for height) nor stunted ( $<-2 z$ scores for height for age). Women and children with known metabolic, chronic and gastrointestinal disease, as well as women and children taking long-term medication (except for oral contraceptives for the women) were not included in the study. Further exclusion criteria were as follows: consumption of vitamin and/or mineral supplements 2 weeks before the study and during the study, blood donation or substantial blood loss within 4 months of the beginning of the study. Women and children were only included as pairs. All women provided written informed consent for themselves and their children. The study was conducted according to the Declaration of Helsinki and ethical approval for the study was provided by the ethical review committees at ETH Zurich as well as the Ministry of Health in Haiti. The study was registered at clinicaltrials.gov (NCT02096250).

\section{Study design}

The flow of study participants is shown in Fig. 1. A randomised cross-over design with single meals was chosen for test meals A (FeFum) and B (NaFeEDTA), where each women and child served as their own control. This design was chosen to eliminate a potential effect of the first test meal on Fe absorption of the second meal. Test meal C (FeFum + NaFeEDTA) was given to all the women at the same time point for technical reasons. In total, each woman consumed three test meals and each child consumed two meals.

In the week before test meal consumption, interested study participants were invited to a community health centre in

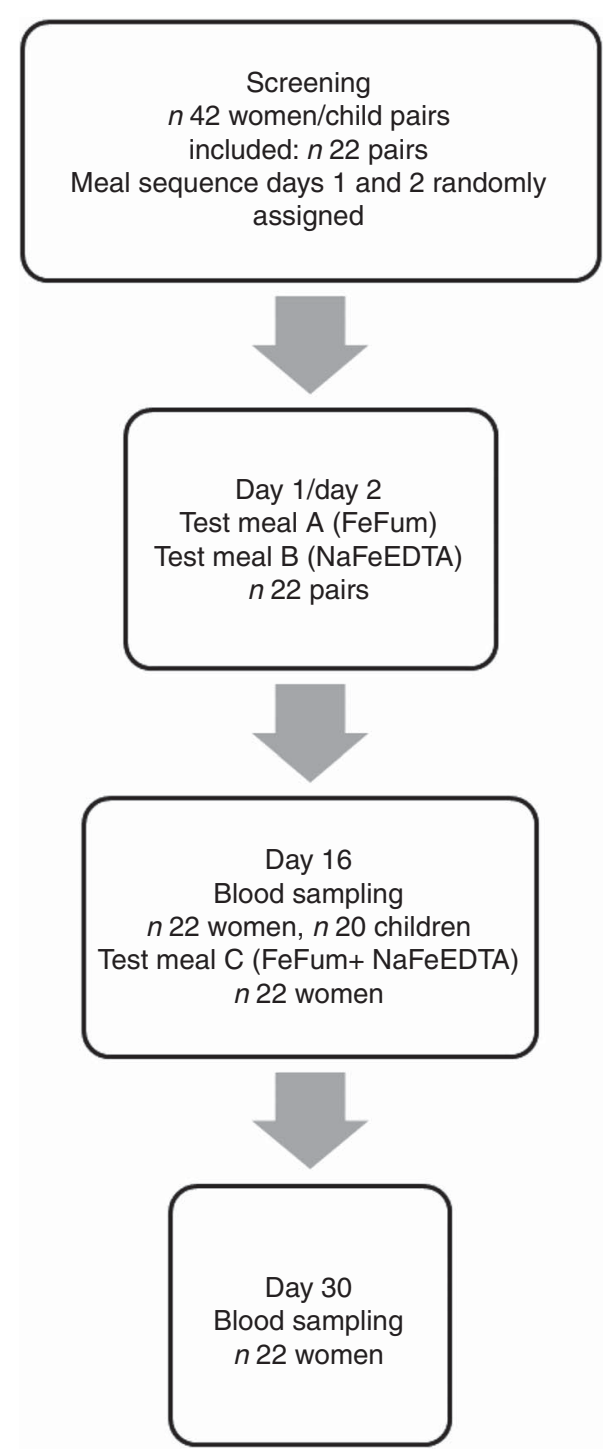

Fig. 1. Study design and participant flow chart. FeFum, ferrous fumarate; FeFum + NaFeEDTA, ferrous fumarate and sodium iron EDTA at a 1:1 ratio for iron. 
Port au Prince for an information session. They had to present at the health centre in the morning after an overnight fast (no food and drinks after midnight). The study was explained to them in detail by the staff of the Ministry of Health of Haiti. After the information, each woman was individually talking to one of the investigators and informed consent was obtained from those women still willing to participate. Consenting women and their children were directly screened: weight and height were measured and the general health status was assessed using a questionnaire. Following this procedure, women had to provide a small urine sample for a pregnancy test. In addition, a venous blood sample was collected ( $4 \mathrm{ml}$ into a heparin-coated tube) for baseline measurements of Fe status, inflammation and presence of $H$. pylori.

On all study days, study participants presented at the health centre in the morning after an overnight fast (no food or drinks after midnight). In the week after screening, study participants presented at the health centre on 2 consecutive days for the consumption of test meals $\mathrm{A}$ and $\mathrm{B}$, one on each day. The order of the two meals was randomised for each participant by using a random number list generated in EXCEL. A period of $14 \mathrm{~d}$ after consumption of the second test meal, a venous blood sample ( $4 \mathrm{ml}$ into an EDTA-coated tube and $4 \mathrm{ml}$ into a heparin-coated tube) was taken from each participant (women and children) for the determination of $\mathrm{Hb}$, Fe-stable isotopes incorporated into erythrocytes as well as Fe and inflammatory status. Directly following blood sampling, test meal $\mathrm{C}$ was consumed by the women only. A last blood sample was taken from the women another $14 \mathrm{~d}$ later in the same way as described above. All test meals were labelled with the stable Fe isotopes ${ }^{57} \mathrm{Fe}$ and ${ }^{58} \mathrm{Fe}$. Per test meal, $4 \mathrm{mg}$ of $\mathrm{Fe}$ was administered to the women and $2 \mathrm{mg}$ of Fe was administered to the children. ${ }^{57} \mathrm{Fe}$ was used to label the FeFum in test meal $\mathrm{A}$ and ${ }^{58} \mathrm{Fe}$ to label the NaFeEDTA in test meal B. In test meal C, both Fe compounds were labelled with ${ }^{57} \mathrm{Fe}$. The amount of Fe used in the test meal was chosen to simulate the fortification level currently discussed by the Haitian government.

\section{Test meals}

All test meals consisted of white bread rolls with processed cream cheese (La Vache qui Rit; Fromageries Bel) and a carbonated beverage (Sékola Citron; Séjourné). For each test meal, the women received two bread rolls (approximately $94 \mathrm{~g}$ ) with $30 \mathrm{~g}$ of cream cheese and $410 \mathrm{~g}$ of Sékola Citron. The children received one bread roll (approximately $47 \mathrm{~g}$ ) with $15 \mathrm{~g}$ of cream cheese and $160 \mathrm{~g}$ of the same beverage. The bread rolls were specifically prepared for the study by a local baker using non-fortified wheat flour ( $77 \%$ extraction) from the Haitian mill. The bread rolls were prepared from one single batch of flour collected directly at the mill but at two time points (for test meals $\mathrm{A}$ and $\mathrm{B}$ together and again for test meal C). Bread rolls were re-heated in an oven before consumption and cut into halves. Isotopes, pre-weighed in individual doses, were added to one side of the bread before spreading the cheese on top using a disposable plastic knife for each participant. The FeFum $\left({ }^{57} \mathrm{Fe}\right)$ was added in a powder form from glass vials directly onto the bread. After emptying the vial, it was rinsed twice with $0.25 \mathrm{ml}$ water, which was also poured on the bread. The NaFeEDTA was added in a liquid form from Teflon vials directly onto the bread. The vials were rinsed once with $0.5 \mathrm{ml}$ of water, which was also poured on the bread.

\section{Preparation of isotopically labelled iron}

Isotopically labelled ${ }^{57} \mathrm{Fe}$ fumarate was prepared from isotopically enriched elemental Fe (Dr Paul Lohmann) and isotopically labelled $\mathrm{Na}^{58}$ FeEDTA and $\mathrm{Na}^{57}$ FeEDTA was prepared using the method described by Loots et al. ${ }^{(8)}$. Isotopic enrichment was $96.3 \%$ for ${ }^{57} \mathrm{Fe}$ and $99 \cdot 86 \%$ for ${ }^{58} \mathrm{Fe}$.

\section{Blood analysis}

Blood samples were stored in a cool box at the health centre until transport to the laboratory following completion of sampling each day. All heparinised samples were centrifuged and plasma aliquoted and stored at $-20^{\circ} \mathrm{C}$ until analysis. EDTA blood was used for the analysis of $\mathrm{Hb}$ on the day of sampling using an automated haematology analyser (Sysmex KX-21N; Sysmex). The remaining EDTA blood was aliquoted and stored at $-20^{\circ} \mathrm{C}$ until analysis of isotopic composition. All samples were shipped to ETH Zurich on dry ice for analysis. Serum ferritin (SF), soluble transferrin receptor (TfR), C-reactive protein (CRP), $\alpha 1$-acid glycoprotein (AGP) and retinol binding protein (RBP) were determined using the multiplex ELISA method described by Erhardt et al. ${ }^{(9)}$. H. pylori was determined using a qualitative rapid test kit (D-HPD20, Rapid Anti-H. Pylori Test; Rapid Labs). This test has a sensitivity of $94.88 \%$ and a specificity of $95.38 \%$ compared with the standard ELISA method.

Body Fe stores (BIS) were calculated from SF and TfR using the following equation: BIS $(\mathrm{mg} / \mathrm{kg})=-(\log (\mathrm{TfR}(\mathrm{mg} / \mathrm{l}) /(\mathrm{SF}$ $(\mu \mathrm{g} / \mathrm{l}) / 1000))-2 \cdot 8229) / 0 \cdot 1207$. Acute inflammation was defined as CRP concentrations $>5 \mathrm{mg} / \mathrm{l}$ for both women and children, and chronic inflammation was defined as AGP $>1 \mathrm{~g} / \mathrm{l}$. Fe deficiency was defined using either SF or TfR with the following cut-offs: mothers: SF $<15 \mu \mathrm{g} / 1$ in subjects without inflammation and $\mathrm{SF}<30 \mu \mathrm{g} / \mathrm{l}$ in subjects with elevated CRP or AGP, TfR $>8.3 \mathrm{mg} / \mathrm{l}$; children: $\mathrm{SF}<12 \mu \mathrm{g} / \mathrm{l}$ and $\mathrm{SF}<30 \mu \mathrm{g} / \mathrm{l}$ in subjects with elevated CRP or AGP, TfR $>8.3 \mathrm{mg} / \mathrm{l}$. Vitamin A deficiency was defined as RBP concentrations $<0.7 \mu \mathrm{mol} / 1$ and moderate vitamin A deficiency was defined as RBP $<1.05 \mu \mathrm{mol} / \mathrm{l}$.

Each isotopically enriched blood sample was analysed in duplicate for its isotopic composition under chemical blank monitoring. Whole blood was mineralised by microwave digestion and Fe was separated by anion-exchange chromatography, followed by a precipitation step with ammonium hydroxide $^{(10)}$. All isotopic analyses were performed by negative thermal-ionisation MS (MAT 262; Finnigan MAT).

\section{Calculation of iron absorption}

Total circulating Fe was calculated based on blood volume, which was estimated based on weight and height using the equation by Brown et al. ${ }^{(11)}$. For the calculation of fractional absorption, $80 \%$ incorporation of the absorbed Fe into the erythrocytes was assumed ${ }^{(10)}$. For the calculation of absorbed Fe from test meal $\mathrm{C}$, the isotopic composition in the blood sample taken on day 16 was used as the baseline. 


\section{Statistical analysis}

Based on data from previous Fe-absorption studies at our laboratory, we calculated a sample size of twenty subjects to be sufficient to detect a difference of $30 \%$ in fractional Fe absorption between meals with a $\beta$ of 0.8 and an $\alpha$ of 0.05 . To account for potential dropouts during the study, we increased the sample size by $10 \%$ and aimed to include twenty-two women with their children. Statistical analysis was done using SPSS 22 (IBM SPSS Statistics). All data were checked for normal distribution before analysis. Normally distributed data are presented as means and standard deviations (age, height, weight, $\mathrm{Hb}, \mathrm{BIS}$ ) and non-normally distributed data are presented as geometric means and $95 \% \mathrm{CI}$ (SF, TfR, CRP, AGP, RBP, fractional Fe absorption). Comparisons of fractional Fe absorption between test meals were done using repeated-measures ANOVA with post hoc Bonferroni correction for the mothers and a paired-samples $t$ test for the children. Associations between Fe absorption and parameters of Fe status as well as inflammatory status were investigated using Pearson's correlations. The level of significance was defined as $P<0 \cdot 05$.

\section{Results}

The study population consisted of twenty-two women (mean age 28.3 (sD 7.3) years) and their twenty-two children aged between 2.5 and 5 years (mean age 3.6 (sD 0.7 ) years). All women consumed all three test meals, but absorption results from two women had to be excluded because no enrichment could be detected in the final blood samples. Absorption data of three children are missing for test meal A and of two for test meal $\mathrm{B}$. Three of those values are missing because the children did not consume the entire test meal with the isotopes and two because no blood sampling was possible from the child at endpoint. Baseline blood samples were available from all women and children.

Anthropometric characteristics as well as Fe and inflammatory status of all study participants are shown in Table 1 . Seven children and one woman had CRP concentrations $>5 \mathrm{mg} / \mathrm{l}$, indicating acute inflammation. Furthermore, five mothers and fourteen children had elevated AGP concentrations $(>1 \mathrm{~g} / \mathrm{l})$. Seven of the children had $\mathrm{Hb}$ concentrations $<110 \mathrm{~g} / \mathrm{l}$ and were thus diagnosed as anaemic, and five women had $\mathrm{Hb}$ concentrations $<120 \mathrm{~g} / \mathrm{l}$, the cut-off for anaemia in women. Based on a low SF, $27 \%$ of women and none of the children were Fe deficient. Based on an elevated TfR, $23 \%$ of women and $64 \%$ of children were Fe deficient.

Geometric mean fractional Fe absorption from the different test meals and the total amount of Fe absorbed from the labels are shown in Table 2 . Fractional absorption was not significantly different comparing mothers with children for either test meal. For both groups, fractional absorption was significantly higher from meal B (NaFeEDTA) compared with meal A (FeFum) $(P=0.029)$. Absorption from test meal C (FeFum + NaFeEDTA $)$ was not significantly different from test meals A or B $(P>0.05)$, and showed an intermediate value. Fe absorption of the women from all three test meals is shown in Fig. 2. The total amount of Fe absorbed from the labels was not significantly different
Table 1. General characteristics of the study population (Mean values and standard deviations; geometric means and 95\% confidence intervals)

\begin{tabular}{|c|c|c|c|c|}
\hline & \multicolumn{2}{|c|}{ Women } & \multicolumn{2}{|c|}{ Children } \\
\hline & Mean & SD & Mean & SD \\
\hline$n$ & \multicolumn{2}{|c|}{22} & \multicolumn{2}{|c|}{22} \\
\hline Age (years) & $24 \cdot 4$ & $12 \cdot 0$ & 3.41 & 1.02 \\
\hline Height (m) & 1.60 & 0.045 & 0.99 & 0.082 \\
\hline Weight $(\mathrm{kg})$ & 54.5 & 5.95 & $14 \cdot 6$ & $2 \cdot 27$ \\
\hline $\mathrm{Hb}(\mathrm{g} / \mathrm{l})$ & 126 & $17 \cdot 5$ & 113 & $12 \cdot 4$ \\
\hline \multicolumn{5}{|l|}{ Serum ferritin $(\mu \mathrm{g} / \mathrm{l})$} \\
\hline Mean & \multicolumn{2}{|c|}{$32 \cdot 2$} & \multicolumn{2}{|c|}{54.9} \\
\hline $95 \% \mathrm{Cl}$ & \multicolumn{2}{|c|}{$20 \cdot 9,48 \cdot 8$} & \multicolumn{2}{|c|}{$46 \cdot 2,64 \cdot 2$} \\
\hline \multicolumn{5}{|l|}{ Transferrin receptor (mg/l) } \\
\hline Mean & \multicolumn{2}{|c|}{$7 \cdot 67$} & \multicolumn{2}{|c|}{8.97} \\
\hline $95 \% \mathrm{Cl}$ & \multicolumn{2}{|c|}{$6.56,9.28$} & \multicolumn{2}{|c|}{$8.03,10.02$} \\
\hline Body Fe stores (mg/kg body weight) & 3.69 & $4 \cdot 71$ & $5 \cdot 05$ & 1.72 \\
\hline \multicolumn{5}{|l|}{ CRP (mg/l) } \\
\hline Mean & \multicolumn{2}{|c|}{0.79} & \multicolumn{2}{|c|}{$1 \cdot 35$} \\
\hline $95 \% \mathrm{Cl}$ & \multicolumn{2}{|c|}{$0.46,1.48$} & \multicolumn{2}{|c|}{$0.72,2.47$} \\
\hline \multicolumn{5}{|l|}{ AGP (g/l) } \\
\hline Mean & \multicolumn{2}{|c|}{0.86} & \multicolumn{2}{|c|}{$1 \cdot 12$} \\
\hline $95 \% \mathrm{Cl}$ & \multicolumn{2}{|c|}{$0.74,1.04$} & \multicolumn{2}{|c|}{$0.96,1.32$} \\
\hline \multicolumn{5}{|l|}{$\operatorname{RBP}(\mu \mathrm{mol} / \mathrm{l})$} \\
\hline Mean & \multicolumn{2}{|c|}{$1 \cdot 22$} & \multicolumn{2}{|c|}{0.95} \\
\hline $95 \% \mathrm{Cl}$ & \multicolumn{2}{|c|}{$1.09,1.36$} & \multicolumn{2}{|c|}{$0.84,1.05$} \\
\hline
\end{tabular}

CRP, C-reactive protein, AGP, a1-acid glycoprotein; RBP, retinol binding protein.

comparing the three meals in women $(P>0 \cdot 05)$, while it was significantly higher in the meal with NaFeEDTA compared to FeFum in children $(P=0.002)$

In all, nineteen of the women were $H$. pylori positive and only two were negative. Of the children, thirteen were $H$. pylori positive and eight were negative (for the remaining children, sufficient serum was not available to determine an infection). The Fe-absorption values in women and children grouped by infection status are shown in Table 3 . There was no significant difference in Fe absorption comparing H. pylori positive with negative study participants among both women and children. However, the small numbers of women who were $H$. pylori negative limit comparisons in this group. When comparing $\mathrm{Fe}$ absorption between $H$. pylori-positive and -negative study participants, the combined data from both women and children for test meals $\mathrm{A}$ and $\mathrm{B}$ showed no significant differences $(P=0.226$ for meal A and $P=0.397$ for meal B).

Fe absorption was significantly higher from the NaFeEDTA meal compared with the FeFum meal in the H. pylori-positive children $(P=0 \cdot 010)$. The difference was not significant in the negative children $(P=0 \cdot 113)$. The differences between the three meals were not significant in either group of women. In mothers, $\log \mathrm{Fe}$ absorption from both test meals was significantly negatively correlated with SF, BIS, CRP and AGP (all $\log$ data, $P<0 \cdot 05)$. Furthermore, $\log$ Fe absorption from test meal B was significantly positively correlated with $\log$ TfR $(r 0.567$, $P=0.006)$, whereas the correlation was not significant for test meal A $(r$ 0.376, $P=0.085)$. In children, the only significant correlation was between log Fe absorption from test meal A and $\log$ CRP $(r-0.483, P=0.036)$. In a linear stepwise regression model with $\mathrm{Fe}$ absorption as the dependent variable and CRP, AGP, BIS and H. pylori as independent variables, only 
Table 2. Fractional iron absorption and amount of iron absorbed from different test meals in mothers and their children in Haiti (Geometric means and $95 \%$ confidence intervals)

\begin{tabular}{|c|c|c|c|c|c|c|}
\hline & \multicolumn{2}{|c|}{ Meal A (Fe fumarate) } & \multicolumn{2}{|c|}{ Meal B (NaFeEDTA) } & \multicolumn{2}{|c|}{ Meal C (Fe fumarate + NaFeEDTA) } \\
\hline & Mean & $95 \% \mathrm{Cl}$ & Mean & $95 \% \mathrm{Cl}$ & Mean & $95 \% \mathrm{Cl}$ \\
\hline Mothers $(n)$ & \multicolumn{2}{|c|}{22} & \multicolumn{2}{|c|}{22} & \multicolumn{2}{|c|}{20} \\
\hline Fe absorption (\%) & $9 \cdot 24^{a}$ & $6 \cdot 35,13.44$ & $13.06^{b}$ & $9.23,19.10$ & $11.09^{a, b}$ & $7 \cdot 45,17 \cdot 34$ \\
\hline Fe absorbed (mg) & $0.36^{\mathrm{a}}$ & $0.26,0.50$ & $0.51^{\mathrm{a}}$ & $0.35,0.72$ & $0.44^{\mathrm{a}}$ & $0.30,0.66$ \\
\hline Children $(n)$ & \multicolumn{2}{|c|}{19} & \multicolumn{2}{|c|}{20} & & \\
\hline Fe absorption (\%) & $9 \cdot 26^{a}$ & $7 \cdot 00,12 \cdot 31$ & $12 \cdot 99^{b}$ & $9 \cdot 18,18.39$ & & \\
\hline Fe absorbed (mg) & $0 \cdot 19^{a}$ & $0.14,0.25$ & $0 \cdot 26^{\mathrm{b}}$ & $0.18,0.36$ & & \\
\hline
\end{tabular}

NA, not applicable.

${ }^{\mathrm{a}, \mathrm{b}}$ Mean values with unlike superscript letters were significantly different (repeated-measures ANOVA with post hoc Bonferroni correction for the mothers, paired-samples $t$ test for the children, $P<0.05)$.

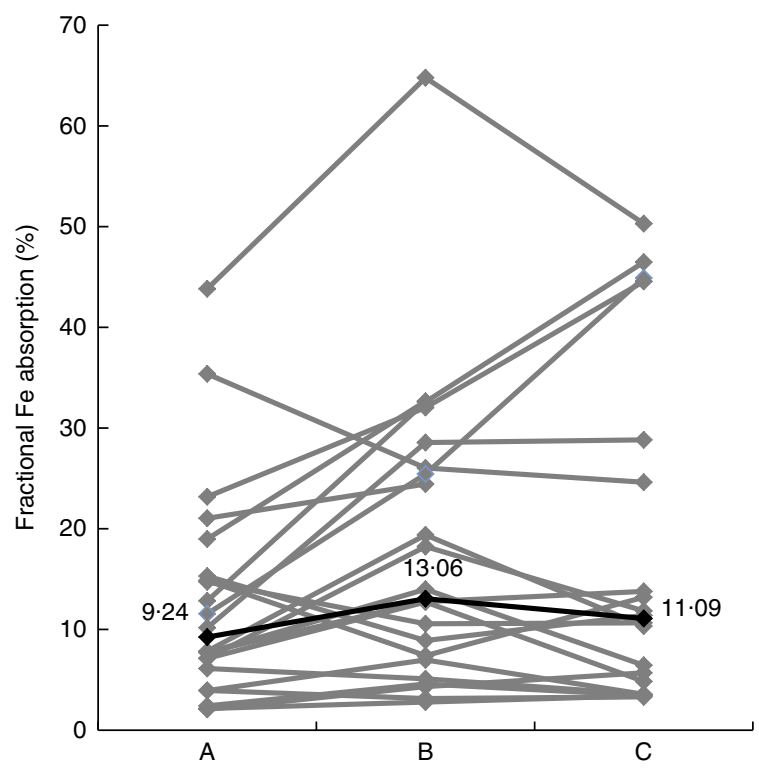

Fig. 2. Fractional iron absorption in mothers from three different iron compounds in an iron absorption study in Haiti $(n$ 22). A, ferrous fumarate; $\mathrm{B}, \mathrm{NaFeEDTA}$; C, ferrous fumarate + NaFeEDTA.

CRP remained a significant predictor of Fe absorption from test meal A (mothers (CRP): $R^{2} 0.337, P=0.006, \beta=-0.581$; children (CRP): $\left.R^{2}=0.233, P=0.036, \beta=-0.483\right)$. The overall predictive value of the model increased with all independent variables included (mothers: $r^{2}$ 0.447, children: $r^{2} 0 \cdot 295$ ), but none of them showed a significant prediction independently (all $P>0 \cdot 05$ ). Using SF instead of BIS in the regression model did not change the results.

\section{Discussion}

Wheat flour is the vehicle most frequently chosen for large-scale Fe-fortification programmes and programmes were in place or in planning in seventy-eight countries worldwide in $2008^{(12)}$. In the draft of the national flour fortification programme of Haiti, it is suggested to use $30 \mathrm{mg}$ Fe in the form of NaFeEDTA per kg of flour (J Marhone, unpublished results). However, NaFeEDTA is the most expensive of the common Fe fortificants and the additional costs may jeopardise the success of the programme. Furthermore, as the flour produced and used in Haiti is lowextraction flour ( $77 \%$ extraction) with a relatively low phytic acid content, the benefit of using NaFeEDTA over other fortificants such as FeFum is unclear. In this study, we have therefore investigated the bioavailability of NaFeEDTA, FeFum, as well as a combination of the two, from a test meal based on wheat flour in young women and their children in Haiti.

Our results show that despite the low extraction rate of the flour, NaFeEDTA was significantly better absorbed (+40\%) by both women and children compared with FeFum. Considering an estimated daily consumption of wheat flour in adults of $120 \mathrm{~g}$, a fortification level of $30 \mathrm{mg} \mathrm{Fe} / \mathrm{kg}$ and the measured $\mathrm{Fe}$ bioavailability in this study in women, the anticipated amount of absorbed Fe would be $0.47 \mathrm{mg} / \mathrm{d}$ for NaFeEDTA and $0.33 \mathrm{mg} / \mathrm{d}$ for FeFum. Assuming daily Fe needs of women of childbearing age of $1.4 \mathrm{mg}$, this absorbed amount would only cover $33 \%$ in the case of NaFeEDTA and $24 \%$ in the case of FeFum and may therefore be insufficient to achieve adequate Fe nutrition in the population. Increasing the amount of absorbed Fe could either be achieved by improving the bioavailability or by increasing the fortification level. The WHO recommendation for wheat flour fortification in low-extraction flour and with a consumption of $75-149 \mathrm{~g}$ flour/d is $40 \mathrm{mg}$ Fe in the form of NaFeEDTA/ $\mathrm{kg}$ flour or $60 \mathrm{mg} \mathrm{Fe}$ as FeFum/kg flour ${ }^{(13)}$. Using these fortification levels, based on our absorption data, the anticipated amount of absorbed Fe from $120 \mathrm{~g}$ wheat flour would be $0.63 \mathrm{mg}$ when using NaFeEDTA and $0.67 \mathrm{mg}$ for FeFum. Thus, using a $50 \%$ higher fortification level with FeFum might result in an equal amount of absorbed $\mathrm{Fe}$ and therefore could be more cost-effective.

An advantage of a fortification mixture of FeFum and NaFeEDTA is that the EDTA moiety may enhance Fe absorption from both Fe compounds as well as the native Fe in the meal. In infants and children consuming inhibitory meals fortified with $\mathrm{FeSO}_{4}$, the addition of NaFeEDTA or $\mathrm{Na}_{2}$ EDTA enhances $\mathrm{Fe}$ absorption by about $50 \%{ }^{(14-16)}$. Whether EDTA can enhance Fe absorption from FeFum is uncertain ${ }^{(17,18)}$. In our study, the absorption from a combination of NaFeEDTA and FeFum did not differ significantly from FeFum alone, suggesting that, in lowextraction wheat flour, there is no strong enhancing effect of the EDTA moiety of Fe absorption from co-fortified FeFum.

In acute and chronic inflammation, the concentrations of cytokines, such as IL-6, are increased, stimulating hepcidin production $^{(19,20)}$. Increased circulating hepcidin concentrations can then reduce dietary Fe absorption ${ }^{(21)}$. In this study, a high number of subjects, especially in the group of children, showed 
Table 3. Fractional iron absorption comparing Heliobacter pylori-negative and -positive subjects ${ }^{\star}$ (Geometric means and $95 \%$ confidence intervals)

\begin{tabular}{|c|c|c|c|c|c|c|}
\hline & \multicolumn{2}{|c|}{ Meal A (Fe fumarate) } & \multicolumn{2}{|c|}{ Meal B (NaFeEDTA) } & \multicolumn{2}{|c|}{ Meal C (Fe fumarate $+\mathrm{NaFeEDTA})$} \\
\hline & Mean & $95 \% \mathrm{Cl}$ & Mean & $95 \% \mathrm{Cl}$ & Mean & $95 \% \mathrm{Cl}$ \\
\hline \multicolumn{7}{|l|}{ Mothers } \\
\hline Negative $(n 2)$ & 5.52 & $3.93,7.75$ & 9.43 & $6 \cdot 97,12 \cdot 76$ & 7.00 & $3.56,13.78$ \\
\hline Positive ( $n$ 19) & $10 \cdot 47$ & $7 \cdot 38,14 \cdot 88$ & $14 \cdot 28$ & $9 \cdot 60,20 \cdot 63$ & 12.53 & $7 \cdot 89,19 \cdot 16$ \\
\hline \multicolumn{7}{|l|}{ Children } \\
\hline Negative $(n 7)$ & 8.02 & $5.98,10.58$ & 11.24 & $6 \cdot 15,19 \cdot 95$ & & \\
\hline Positive (n 13) & 10.07 & $6.79,14.98$ & $14 \cdot 11$ & $8 \cdot 76,23 \cdot 68$ & & \\
\hline
\end{tabular}

NA, not applicable.

${ }^{*}$ For mothers and children and for each test meal, values were compared between $H$. pylori-positive and -negative subjects using an independent-samples $t$ test. No significant differences were detected for any of the groups $(P>0.05)$.

either acute or chronic inflammation as determined by CRP and AGP, respectively, which may have influenced the results of the Fe-absorption studies. This is suggested by the significant negative associations shown between $\mathrm{Fe}$ absorption and inflammatory markers in both groups. Another important predictor of hepcidin and consequently $\mathrm{Fe}$ absorption is $\mathrm{Fe}$ status $^{(19,20)}$. In the women, where only five subjects were affected by inflammation, the expected inverse relationship between Fe absorption and Fe status was apparent: there were significant associations between Fe absorption and Fe status ( $\mathrm{SF}$ and $\mathrm{TfR}$ ). In contrast, in the children, these associations were not visible, possibly because of the much higher rate of inflammation, and the confounding effect of inflammation on $\mathrm{SF}$, an acute-phase protein ${ }^{(22)}$.

H. pylori infection has repeatedly been associated with Fe-deficiency anaemia ${ }^{(23-25)}$. Although these conditions may simply cluster together in low-resource settings, one possible explanation for a causal effect is reduced Fe absorption from the diet as a result of impaired gastric acid secretion ${ }^{(7,24)}$. Ciacci et al. ${ }^{(6)}$ investigated Fe absorption using the serum Fe appearance method in $H$. pylori-positive and -negative adults. Fe appearance was significantly higher in $H$. pylori-negative compared with -positive subjects and it improved significantly in the latter group after antibiotic treatment. However, in this study, the administered Fe was already in the ferrous form $\left(\mathrm{Fe}^{2+}\right)$, whereas most dietary non-haeme $\mathrm{Fe}$ is in the ferric form $\left(\mathrm{Fe}^{3+}\right)$ and needs to be reduced before absorption into enterocytes ${ }^{(3)}$. Thus, it is unclear whether the effect of $H$. pylori infection on absorption from the $\mathrm{Fe}$ administered in the study by Ciacci et al. ${ }^{(6)}$ would be comparable with its effect on dietary Fe.

Sarker et $a l^{(7)}$ investigated gastric acid secretion and $\mathrm{Fe}$ absorption in children in Bangladesh. Even though they found lower gastric acid output in $H$. pylori-infected children, Fe absorption from test meals with FeFum and ferrous sulphate did not differ significantly from the non-infected children. In our present study there was a tendency towards higher, rather than lower Fe absorption in H. pylori-positive subjects, both in the group of mothers and in children. However, the sample sizes in the subgroups were small; there were only two $H$. pylori-negative mothers and seven $H$. pylori-negative children, which made a statistical comparison difficult. Nevertheless, the trends observed were similar to those observed by Sarker et al., where absorption values for $H$. pylori-negative subjects were also lower for ferrous sulphate, although not significantly ${ }^{(7)}$. The pathogenesis of
H. pylori infection shows large variations depending on the virulence of the infecting $H$. pylori strain, the extent and type of the host immune response as well as other modulating factors such as diet and smoking. Depending on the location and type of gastric inflammation, $H$. pylori infection can result in increased or decreased secretion of gastric acid. Which kind of inflammation develops is not well understood to date, but host genetics as well as environmental factors seem to play a role besides strain type ${ }^{(5)}$. We did not determine gastric acid secretion in our study, but one possible explanation for our findings may be that our subjects may have higher rather than lower gastric acid secretion with H. pylori infection.

Our study has several strengths. We used Fe-stable isotopes to accurately quantify Fe bioavailability from Haitian wheat flour in both young women and children, two key target groups for Fe-fortification programmes, and directly compared three different Fe fortificants. Our study also has limitations: not all of the subjects were Fe deficient and this may have contributed towards lower fractional absorption of the fortificant Fe; the low numbers of $H$. pylori-negative subjects limited comparisons based on $H$. pylori status and the power of the study would allow us to only detect a difference of at least $30 \%$ in fractional $\mathrm{Fe}$ absorption between meals. In conclusion, in Haitian women and children consuming low-extraction wheat flour, Fe absorption from NaFeEDTA was $40 \%$ higher than from FeFum, and the combination of FeFum and NaFeEDTA did not lead to a significant increase in $\mathrm{Fe}$ absorption compared with FeFum alone. In the context of Haiti, where the high costs of NaFeEDTA may not be affordable, the use of FeFum $60 \mathrm{mg} \mathrm{Fe} / \mathrm{kg}$ flour may be a preferable, cost-effective fortification strategy.

\section{Acknowledgements}

The authors would like to thank all women and children who participated in the study. Further thanks are due to the study team of the Ministère de la Santé Publique et de la Population in Port au Prince for their support during the study and to Christophe Zeder, Adam Krzystek and Jürgen Erhardt for their support with sample analysis.

This study was funded by the International Atomic Energy Agency (IAEA).

I. H.-A., C. U. L. and M. B. Z. formulated the research question and designed the study; I. H.-A., K. E. and J. M. P. carried out the field work and collected the samples; Y. R. was responsible for 
laboratory analyses; and I. H.-A. carried out the statistical analysis and wrote the first draft of the manuscript. All authors have reviewed the manuscript.

None of the authors has any conflicts of interest to declare.

\section{References}

1. World Health Organization (2015) The Global Prevalence of Anaemia in 2011. Geneva: WHO.

2. United Nations Development Programme (2015) International Human Development Indicators. http://hdr.undp.org/en/ countries (accessed October 2015).

3. Zimmermann MB \& Hurrell RF (2007) Nutritional iron deficiency. Lancet 370, 511-520.

4. Allen L, de Benoist B, Dary O, et al., (editors) (2006) Guidelines on Food Fortification with Micronutrients. Geneva: WHO Press.

5. Atherton JC (2006) The pathogenesis of Heliobacter pyloriinduced gastro-duodenal diseases. Annu Rev Pathol 1, 63-96.

6. Ciacci C, Sabbatini F, Cavallaro R, et al. (2004) Helicobacter pylori impairs iron absorption in infected individuals. Digest Liver Dis 36, 455-460.

7. Sarker SA, Davidsson L, Mahmud H, et al. (2004) Helicobacter pylori infection, iron absorption, and gastric acid secretion in Bangladeshi children. Am J Clin Nutr 80, 149-153.

8. Loots DT, Lieshout MV \& Lachmann G (2007) Sodium iron(III) ethylenediaminetetraacetic acid synthesis to reduce iron deficiency globally. Eur J Clin Nutr 61, 287-289.

9. Erhardt JG, Estes JE, Pfeiffer CM, et al. (2004) Combined measurement of ferritin, soluble transferrin receptor, retinol binding protein, and C-reactive protein by an inexpensive, sensitive, and simple sandwich enzyme-linked immunosorbent assay technique. J Nutr 134, 3127-3132.

10. Walczyk T, Davidsson L, Zavaleta N, et al. (1997) Stable isotope labels as a tool to determine the iron absorption by Peruvian school children from a breakfast meal. Fresenius J Anal Chem 359, 445-449.

11. Brown E, Hopper J Jr, Hodges JL Jr, et al. (1962) Red cell, plasma, and blood volume in the healthy women measured by radiochromium cell-labeling and hematocrit. J Clin Invest 41, 2182-2190.

12. Hurrell RF, Ranum P, de Pee S, et al. (2010) Revised recommendations for iron fortification of wheat flour and an evaluation of the expected impact of current national wheat flour fortification programs. Food Nutr Bull 31, S7-S21.
13. World Health Organization, Food and Agriculture Organization \& United Nations International Children's Emergency Fund. et al. (2009) Recommendations on Wheat and Maize Flour Fortification. Meeting Report: Interim Consensus Statement. Geneva: WHO.

14. Davidsson L, Walczyk T, Zavaleta N, et al. (2001) Improving iron absorption from a Peruvian school breakfast meal by adding ascorbic acid or Na(2)EDTA. Am J Clin Nutr 73, 283-287.

15. Chang SY, Huang ZW, Ma YX, et al. (2012) Mixture of ferric sodium ethylenediaminetetraacetate (NaFeEDTA) and ferrous sulfate: an effective iron fortificant for complementary foods for young Chinese children. Food Nutr Bull 33, 111-116.

16. Chavasit V, Porasuphatana S, Suthutvoravut U, et al. (2015) Iron bioavailability in 8-24-month-old Thai children from a micronutrient-fortified quick-cooking rice containing ferric ammonium citrate or a mixture of ferrous sulphate and ferric sodium ethylenediaminetetraacetic acid. Matern Child Nutr 11, 179-187.

17. Walter T, Pizarro F \& Olivares M (2003) Iron bioavailability in corn-masa tortillas is improved by the addition of disodium EDTA. J Nutr 133, 3158-3161.

18. Fidler MC, Davidsson L, Zeder C, et al. (2003) Iron absorption from ferrous fumarate in adult women is influenced by ascorbic acid but not by Na(2)EDTA. Br J Nutr 90, 1081-1085.

19. Dunn LL, Rahmanto YS \& Richardson DR (2007) Iron uptake and metabolism in the new millennium. Trends Cell Biol 17, 93-100.

20. Viatte L \& Vaulont S (2009) Hepcidin, the iron watcher. Biochimie 91, 1223-1228.

21. Weiss $G$ (2009) Iron metabolism in the anemia of chronic disease. Biochim Biophys Acta 1790, 682-693.

22. World Health Organization \& Centers for Disease Control and Prevention (2007) Assessing the Iron Status of Populations. Geneva: WHO \& CDC.

23. Barabino A, Dufour C, Marino CE, et al. (1999) Unexplained refractory iron-deficiency anemia associated with Helicobacter pylori gastric infection in children: further clinical evidence. J Pediatr Gastroenterol Nutr 28, 116-119.

24. Berg G, Bode G, Blettner M, et al. (2001) Helicobacter pylori infection and serum ferritin: A population-based study among 1806 adults in Germany. Am J Gastroenterol 96, 1014-1018.

25. Marignani M, Angeletti S, Bordi C, et al. (1997) Reversal of long-standing iron deficiency anaemia after eradication of Helicobacter pylori infection. Scand J Gastroenterol 32, 617-622. 